\title{
correspondence
}

\section{The WHO and mosquitoes}

Sir,-We have read with interest your editorial (July 31) on the allegations made by a section of the Indian press and the Public Accounts Committee of the Indian Parliament against the Delhi-based Research Unit on Genetic Control of Mosquitoes whose activities were jointly implemented and supervised by the World Health Organisation and the Indian Council of Medical Research (ICMR).

With regard to the technical aspects of this controversy, you have highlighted the crucial fact that the authors of the allegations failed to read the abundant literature issued by the research unit, either reports or publications, which were made freely available to them, and that they used logic so tenuous that it does not stand up to unprejudiced examination. We might add that they did not even take the trouble to discuss the controversial points with the many Indian scientists carrying out research at the unit.

We should like, however, to complement your analysis by supplying some additional information on other aspects of the controversy, for which the only documentation that you had was that presented by the authors of the allegations.

Dr Jayaraman's assertion that he was refused information on the project by the WHO because "it was sensitive to the Indian press" does not represent the truth. On the contrary, all cooperation was extended to him and a meeting was immediately arranged under the chairmanship of the DirectorGeneral of the ICMR with the Director of the National Institute of Communicable Diseases of India, the unit's Project Leader and Dr Pal of the WHO's Vector Biology and Control Unit at Headquarters, The Chairman invited Dr Jayaraman to raise any questions about the unit's research after he had a chance to see the special issue of the Journal of Communicable Diseases devoted to papers on the unit's work. It was most unfortunate that Dr Jayaraman never availed himself of this offer; had he done so, the fallacies in his subsequent published statements might have been avoided. You have also quoted Dr Jayaraman's allegation that he was "indirectly sounded out for a job as an Information Officer at WHO Headquarters", the implication being that this was done in an effort to appease him. No such offer was made to him; what was offered was the full cooperation of the WHO information services in the preparation of his article. It is noteworthy that Dr Jarayaman did not make this allegation in the press, but only before the Parliamentary Committee.

With reference to the use of chemosterilised mosquitoes, your presentation of the situation is not entirely accurate. The unit's statement that thiotepa residues break down very rapidly in the bodies of mosquitos is not a mere "claim" but is based on investigations, the results of which have been published (LaBrecque, G. C., Bowman, M. C., Patterson, R. S., and Seawright, J. A., Bull. Wld Hlth Org., 47, $675-676 ;$ 1972). The unit's statement that drinking-water wells were never used for the release of chemosterilised pupae is factually correct. Apart from considerations of safety, the use of drinking-water wells (in which Culex fatigans does not normally breed) would have defeated the aim of releasing sterile males at the natural breeding sites, which in the area and season concerned are disused irrigation wells. The toxic effects of the well water on laboratory-reared pupae was discovered not because these were released in the wells, but because treated pupae were placed for emergence in this water in containers which in the initial stages were floating and later suspended above the water.

You sharply criticise WHO's handling of public relations during the controversy. We may point out that as an international organisation the WHO does not make any statement which could be construed as intervention in an internal dispute or a matter falling within the domestic jurisdiction of a member state. So long as this was the case, and the question was under investigation by a Parliamentary Committee in India, it was not considered appropriate to publish on this matter.

Finally, your statement that the WHO has "pulled out" may leave a false impression with your readers. The original agreement between the government of India and the WHO establishing the research unit was for a period of six years, which expired on June 30,1975 . The unit developed much essential methodology, carried out several small scale field trials and assisted in the creation of a core group of Indian scientists fully conversant with all the aspects of the research. What is left to be done is to carry out large scale feasibility studies of new vector control methodology in areas of southern India endemic for mosquitoborne diseases, which does not require the assistance of full-time WHO staff members. It is anticipated that this work will be carried out under Indian leadership now that the WHO has handed over the unit to the Indian Council of Medical Research on the appointed date, with continued WHO technical advice and assistance if requested.

Yours faithfully, F. J. TOMIche

World Health Organisation, Geneva

SiR,-Your leader "Oh, New Delhi; Oh, Geneva" (July 31) might as well have been written by the World Health Organisation's Public Relations staff whom you hold responsible for the bad handling of the Indian press that ultimately, according to you, led to the closure of the Research Unit on Genetic Control of Mosquitoes (GCMU) in New Delhi.

The intention of this letter is not to highlight all the crucial omissions you had made (that would make the letter long) but only to correct a few statements which apparently have been taken out of the handout the GCMU had prepared in defence of its project.

You have dismissed the six-volume Stockholm International Peace Research Institute (SIPRI) series on chemical and biological warfare (CBW) in one sentence by saying that SIPRI "has reported that biological warfare (BW) could be conducted with infected mosquitoes."

The SIPRI series in fact says a lot more on entomological warfare. Like genetic control, it is also in the research stage. Our allegation that data gathered by the GCMU on mosquitoes can help BW research is supported by SIPRI which says that ecological data of mosquitos and dispersal data obtained from field trials are useful in BW.

It is well known that only female mosquitoes pick up and transmit viruses. Your categorical statement that GCMU's "work has been exclusively concerned with males" is however, incorrect. The GCMU was to have released at least 2,000 females a day at Sonepat. The male-female sexing error, as claimed by the GCMU, is $0.25 \%$ and in practice it may be higher. 
Second, dealing predominantly with male mosquitoes need not be a great handicap. A specialist in mosquito ecology can obtain the dispersal pattern of females of a species of mosquito by extrapolating the dispersal data of males.

Your leader gives an erroneous impression that we were the only two "to level accusations of BW." Other witnesses who appeared before the Parliamentary Public Accounts Committee (PAC) belonged to the health and defence ministeries. Of course they will not accuse themselves. But if you had carefully read the PAC report you would have noticed statements made by health officials admitting that both the GCMU project and the Jodhpur project (another WHO venture about which your leader is silent) could provide data useful in BW.

You may be "revolted" by the thought that the US government was using an intermediate organisation (WHO) to learn how to infect the Indians with yellow fever. Do you know that the USA was alleged to have used an FAO expert (an Indian) in 1970 to sabotage Cuban sugar cane research?

Do you know that a US expert working at the Indian Agricultural Research Institute (IARI) here was caught at the India-Pakistan border in 1971 with his luggage containing wheat germ plasm collected by the IARI?

It was unfortunate that articles criticising the GCMU and other projects were interpreted to be anti-American. This was never intended. The bird migration studies supported by the GCMU and the US army at the Bombay Natural History Society exemplified the casual attitude of some to foreign funded research. But many other countries have set up collaborative projects covering agriculture, livestock and the continental shelf.

Although we journalists appeared before the PAC late in the day, the same questions put to us were also put to official witnesses and they were given every opportunity to give answers.

You seem to regard the WHO pulling out from an "important" research project as bad. Bad for whom? Not for India which needs to tackle malaria now and not 40 years hence when genetic control may become viable scientifically-but not economically.

As far as filariasis is concerned, an expert report to the Indian Council of Medical Research had clearly said in 1971 that the strategy is not elimination of the vector Culex fatigansbut protection with drugs of the vulnerable population below the age of 21 in the endemic regions.

Chikungunya and dengue are not major health problems in India (as they were made out to be during the GCMU controversy) and control of Aedes aegypti has the least priority. That dengue gives cross protection against yellow fever is so strongly established (Theiler, Max, Arthropod borne diseases in vertebrates; 1973) that grand projects to eradicate Aedes aegypti-even though foreign-financed and with WHO sanction-can be only anything but scientific.

Arguments that yellow fever did not strike after elimination of Aedes aegypti from Poona in 1953 are too weak to disprove Max Theiler's conclusion that a person immune to dengue is automatically immune to yellow fever. Such arguments are too childish to be taken seriously by the health department of any country. Yellow fever did not come to Poona perhaps because other vectors of yellow fever were also not present, or there were missing links in the epidemiological chain.

If the closing of the GCMU causes concern to British scientists they may well restart the project around London. It is better that sophisticated technologies (genetic manipulation is one) are first tried and developed in advanced countries before they are recommended to developing countries.

Your worries that India will find few opportunities to collaborate with the rest of the scientific world are unwarranted. Right now India collaborates with some 40 countries. Almost every month some science agreement or other is signed. Under such circumstances it is only natural for the PAC to recommend that foreign research in certain areas like weather modification, and oceanography should be scrutinised from the security angle.

The PAC has not banned foreign collaboration in science but has asked for the closer participation of Indian scientists who are at present given subordinate roles and not decision-making or project-management roles in foreign-funded research. The PAC has also called for thorough scrutiny by a governmental clearing body as you yourself have admitted that "almost everything has its military aspect."

We would like to ask, for instance, if the British government will allow a team of foreign scientists to go about surveying Britain's continental shelf, causing artificial earthquakes in "search of minerals", or releasing new strains of pigeons in Trafalgar Square?

$$
\begin{aligned}
& \text { C. Raghavan } \\
& \text { K. S. JaYARAMAN }
\end{aligned}
$$

Press Trust of India Ltd.

New Delhi, India

\section{Unwelcome error}

SiR,- - Something went a little wrong, I am afraid, in the box headed "Wellcome Foundation" in your guide "How Britain Runs its Science" (August 28).

The Wellcome Foundation Limited is the parent company of a British based pharmaceutical group trading as Burroughs Wellcome, Coopers and Calmic around the world. Its chairman is $\mathrm{Mr}$ A. A. Gray. Like any other pharmaceutical group it spends money on its own research and development.

All its shares are owned by a registered charity, The Wellcome Trust, which under the Will of Sir Henry Wellcome, who died in 1936, applies all moneys it receives, as sole shareholder, to the support of medical and allied research in universities and hospitals around the world. The Director of The Wellcome Trust is $\mathrm{Dr} \mathrm{P}$. O. Williams, and I think it is the Trust rather than the foundation that should have been featured in your guide.

The figure you gave for research grants is actually the foundation's expenditure on research and development for the year ended August 31, 1974.

Yours faithfully,

BASIL SAUNDERS

The Wellcome Foundation Ltd, London, UK

ED-Indeed the Wellcome Trust, rather than the foundation, ought to have been featured in our guide. Before anyone starts applying for a slice of the $£ 11.5$ million which the foundation allocated to research and development last year, we had better point out that the trust's spending on research assistance (1972-74) was $£ 1,133,463$.

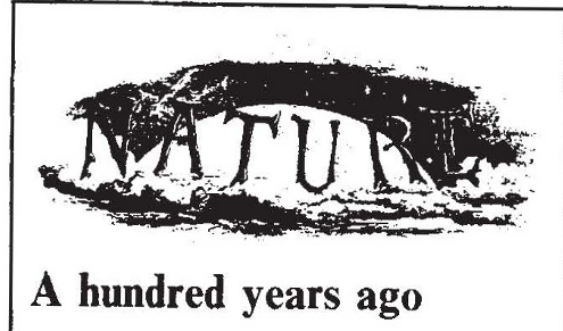

THE German Scientific and Medical Association was opened at Graz on the 17 th inst. Lieut. Weyprecht, of the recent Austrian Arctic Expedition, made a speech deprecating all past Arctic expeditions as adventurous and valueless because they constituted an international rivalry that resulted only in giving names to some ice-bound islands. The speaker, amid general applause, expounded a new programme for making Arctic expeditions more fruitful for natural science, and to enable poorer countries to undertake such expeditions.

from Nature, 12, 260; September, 23, 1875 